\title{
Anti-inflammatory effects of long-chain $n$-3 PUFA in rhinovirus-infected cultured airway epithelial cells
}

\author{
Ahmad Saedisomeolia ${ }^{1,2}$, Lisa G. Wood ${ }^{2,3,4 *}$, Manohar L. Garg ${ }^{1}$, Peter G. Gibson ${ }^{2,3,4}$ and Peter \\ A. B. Wark ${ }^{2,3,4}$ \\ ${ }^{1}$ Nutraceuticals Research Group, School of Biomedical Sciences, University of Newcastle, Newcastle, NSW, Australia \\ ${ }^{2}$ Respiratory and Sleep Medicine, Hunter Medical Research Institute, John Hunter Hospital, Newcastle, NSW, Australia \\ ${ }^{3}$ School of Medicine and Public Health, University of Newcastle, Newcastle, NSW, Australia \\ ${ }^{4}$ Centre for Asthma and Respiratory Disease, Hunter Medical Research Institute, University of Newcastle, Newcastle, NSW, \\ Australia
}

(Received 19 February 2008 - Revised 21 May 2008 - Accepted 22 May 2008 - First published online 17 July 2008)

Long-chain $n$-3 PUFA (LCn-3PUFA) including DHA and EPA, are known to decrease inflammation by inhibiting arachidonic acid (AA) metabolism to eicosanoids, decreasing the production of pro-inflammatory cytokines and reducing immune cell function. The aim of this study was to determine if EPA and DHA reduced the release of inflammatory mediators from airway epithelial cells infected with rhinovirus (RV). Airway epithelial cells (Calu-3) were incubated with EPA, DHA and AA for $24 \mathrm{~h}$, followed by rhinovirus infection for $48 \mathrm{~h}$. IL-6, IL- 8 and interferon$\gamma$-induced protein-10 (IP-10) released by cells were measured using ELISA. Viral replication was measured by serial titration assays. The fatty acid content of cells was analysed using GC. Cellular viability was determined by visual inspection of cells and lactate dehydrogenase release. DHA $(400 \mu \mathrm{M})$ resulted in a significant $16 \%$ reduction in IL-6 release after RV-43 infection, $29 \%$ reduction in IL-6 release after RV-1B infection, $28 \%$ reduction in IP-10 release after RV-43 infection and $23 \%$ reduction in IP-10 release after RV-1B infection. Cellular DHA content negatively correlated with IL-6 and IP-10 release. None of the fatty acids significantly modified rhinovirus replication. DHA supplementation resulted in increased cellular content of DHA at the cost of AA, which may explain the decreased inflammatory response of cells. EPA and AA did not change the release of inflammatory biomarkers significantly. It is concluded that DHA has a potential role in suppressing RV-induced airway inflammation.

EPA: DHA: Inflammation: Rhinovirus: Acute asthma

A low prevalence of chronic inflammatory diseases, such as CHD and asthma, was first reported in 1979 among people of Greenland who had a high intake of long-chain $n-3$ PUFA (LCn-3PUFA) ${ }^{(1)}$. Later this was attributed to the antiinflammatory effect of LCn-3PUFA ${ }^{(2)}$. LCn-3PUFA include EPA and DHA. LCn-3PUFA have been shown to decrease inflammation via (1) inhibiting the inflammatory pathway of arachidonic acid (AA), (2) decreasing production of pro-inflammatory cytokines and (3) reducing immune cell function $^{(3-8)}$.

Long-chain fatty acids are the substrate for production of eicosanoids, which are inflammatory regulators in the human body ${ }^{(9,10)}$. Eicosanoids produced from AA are more inflammatory than those produced by $\mathrm{LC} n-3 \mathrm{PUFA}^{(11-13)}$. For example, leukotriene $\mathrm{B}_{4}$ (produced from $\mathrm{AA}$ ) is 10-30 times more potent as a chemo-attractant than leukotriene $\mathrm{B}_{5}$ (produced from $\mathrm{EPA})^{(4,12,13)}$. Leukotriene $\mathrm{B}_{4}$ increases neutrophil influx, which further potentiates inflammation ${ }^{(14-16)}$. It has been shown that supplementation with EPA and DHA decreases leukotriene $\mathrm{B}_{4}$ production and neutrophil chemotaxis $^{(10)}$. It has also been demonstrated that EPA and DHA reduce synthesis of $\mathrm{AA}$, compete with $\mathrm{AA}$ for incorporation into $s n-2$ position of membrane phospholipids, competing at the cyclo-oxygenase and lipoxygenase enzymes, thereby resulting in a reduction of potent eicosanoid production ${ }^{(4,5)}$.

There is evidence suggesting that increased levels of LC $n$-3PUFA in cellular membranes decreases cytokine production $^{(7,8)}$. In vivo ${ }^{(17,18)}$ and in vitro ${ }^{(19,20)}$ studies show a decrease in inflammatory biomarkers such as IL-6, IL-8 and C-reactive protein following LCn-3PUFA supplementation. Animal studies have also shown a decrease in circulating levels of IL-6, IL-10, TNF- $\alpha^{(21-23)}$, IL-12, IL-1 $\beta$ and interferon- $\gamma^{(22)}$ following LCn-3PUFA supplementation. These anti-inflammatory effects of LCn-3PUFA are attributed to their potent effect on suppression of NF- $\mathrm{B}^{(24-28)}$ most probably via inactivation of signalling through toll-like

Abbreviations: AA, arachidonic acid; $10 \%$ FCS/MEM, minimum essential medium containing $10 \%$ fetal calf serum; IP-10, interferon- $\gamma$-induced protein-10; LCn-3PUFA, long-chain $n$-3 PUFA; RV, rhinovirus; TCID $_{50}$, tissue culture infectious dose at 50\%; TLR, toll-like receptor.

* Corresponding author: Dr Lisa G. Wood, fax +612 49855850, email lisa.wood@newcastle.edu.au 
receptor-2 (TLR-2) ${ }^{(29,30)}$. TLR-2 activation leads to the induction of a signalling cascade that results in the activation of $\mathrm{NF}-\kappa \mathrm{B}^{(31)}$. NF- $\kappa \mathrm{B}$ has been shown to stimulate production of various pro-inflammatory cytokines (reviewed in Blackwell \& Christman ${ }^{(32)}$ ) including IL-6 and IL-8 production in rhinovirus infection $^{(32-34)}$. Recently, it has been found that DHA is more potent than EPA in suppression of NF- $\mathrm{B}^{(26)}$.

It has also been reported that supplementation with high levels of EPA and DHA in vivo decreases (1) lymphocyte proliferation, (2) natural killer cell and monocyte activation and (3) neutrophil and monocyte chemotaxis ${ }^{(7,8,12,19,35,36)}$.

Rhinovirus (RV) is the most common cause of the common cold $^{(37)}$ and the major cause of asthma exacerbation in adults $^{(38)}$ and children ${ }^{(38,39)}$. RV infection can also worsen airway obstruction in asthmatics ${ }^{(40)}$, though the mechanism is not completely understood ${ }^{(41)}$. RV target epithelial cells, in which they replicate ${ }^{(42)}$ and initiate innate immune responses via activation of TLR- $3^{(43,44)}$. As a result, epithelial cells produce various inflammatory mediators that contribute to the host defence and result in increased airway inflammation ${ }^{(41)}$. These include IL- $6^{(8,14,15)}$, IL- $8^{(5,7,8,15,16,45)}$ and interferon$\gamma$-induced protein-10 (IP-10) ${ }^{(41)}$.

Evidence regarding the ability of LCn-3PUFA to improve inflammation in airway epithelial cells infected with RV is lacking. However, some in vitro studies have shown that EPA and DHA can reduce the production of inflammatory biomarkers $^{(18)}$ and decrease inflammation induced by the innate immune stimulus lipopolysaccharide, which acts via TLR- $4^{(24,26,27)}$. These studies found that EPA and DHA suppress $\mathrm{NF}-\kappa \mathrm{B}$ activation ${ }^{(24,26)}$. It is hypothesised that $\mathrm{LCn}$ 3PUFA may also decrease inflammation in airway epithelial cells infected with a virus. The aim of the present study was to determine if EPA and DHA reduced the release of inflammatory mediators from airway epithelial cells infected with RV.

\section{Materials and methods}

\section{Airway epithelial cell culture}

Airway epithelial cells (Calu-3, Passage 40-43, from ATCC, USA) were cultured in minimum essential medium containing $10 \%$ fetal calf serum (10\% FCS/MEM), containing $2 \%$ penicillin-streptomycin, $1 \%$ sodium pyruvate, $1 \%$ non-essential amino acids, $1 \% \mathrm{~L}$-glutamine and $2.2 \mathrm{~g} / 1 \mathrm{NaHCO}_{3}$ (all from Invitrogen Corporation, Carlsbad, CA, USA) at $37^{\circ} \mathrm{C}$ in the presence of $5 \% \mathrm{CO}_{2}$. All experiments were carried out in cells with $>80 \%$ confluence.

\section{Long-chain n-3 PUFA enrichment of cultured epithelial airway cells}

In order to prepare the medium containing DHA, EPA and AA, the method of Nair et al. ${ }^{(46)}$ was employed. Final concentrations of $0,10,200$ and $400 \mu \mathrm{M}$ of each fatty acid (all purchased from Sigma) were dissolved in $0.04 \%$ ethanol ( $400 \mu \mathrm{l}$ ethanol/1 medium) and added to $10 \% \mathrm{FCS} /$ MEM which contains $2.2 \mathrm{~g} / 1 \mathrm{NaHCO}_{3}, 100 \mathrm{U} / \mathrm{ml}$ penicillin, $100 \mu \mathrm{g} / \mathrm{ml}$ streptomycin, $1 \mathrm{mM}$-sodium pyruvate, $0 \cdot 1 \mu \mathrm{M}$-nonessential amino acids, $2 \mathrm{~mm}-\mathrm{L}$-glutamine and $10 \%$ fetal calf serum (all purchased from Invitrogen Corporation). Calu-3 cells were separately incubated with different concentrations
$(0,10,200,400 \mu \mathrm{M})$ of EPA, DHA and AA for $24 \mathrm{~h}$ at $37^{\circ} \mathrm{C}$ in the presence of $5 \% \mathrm{CO}_{2}$.

Rhinovirus infection of Calu-3 cells

After removing from the fatty acid-containing media, cells were infected with RV-43 (multiplicity of infection: 7.2) and RV-1B (multiplicity of infection: 7.2) in fresh $1 \%$ FCS/MEM. Plates were incubated for $48 \mathrm{~h}$ at $37^{\circ} \mathrm{C}$ in the presence of $5 \% \mathrm{CO}_{2}$.

\section{Visual inspection of Calu-3 cells}

Cellular viability of cultured Calu-3 cells was checked after each step of supplementation and infection (Olympus microscope, TL4).

\section{Cytokine analysis}

IL-6, IL-8 and IP-10 concentrations of medium were measured by ELISA (R\&D Systems, Minneapolis, MN, USA) according to the manufacturer's instructions.

\section{Lactate dehydrogenase assay}

Lactate dehydrogenase concentration in the media was measured by the enzymatic method on the Dade Behring RXL Dimension platform (Dade Behring Inc., USA). The assay has a CV of $4.9 \%$ at $350 \mathrm{U} / 1$.

\section{Cellular content of fatty acids}

The Calu-3 cellular content of fatty acids (including EPA, DHA and AA) was analysed using GC. The cell pellet was suspended in $2 \mathrm{ml}$ of a methanol-toluene mixture (4:1, $\mathrm{v} / \mathrm{v})$, containing C19:0 (0.02 mg/ml) and butylated hydroxytoluene $(0 \cdot 12 \mathrm{~g} / \mathrm{l})$ and vortexed vigorously. The samples were methylated by adding $200 \mu \mathrm{l}$ acetyl chloride drop-wise while vortexing, followed by heating to $100^{\circ} \mathrm{C}$ for $1 \mathrm{~h}$. After cooling, the reaction was stopped by adding $5 \mathrm{ml} 6 \%$ $\mathrm{K}_{2} \mathrm{CO}_{3}$ followed by vigorous mixing by vortex. The sample was centrifuged at $3000 \mathrm{~g}$ at $4^{\circ} \mathrm{C}$ for $10 \mathrm{~min}$ to facilitate separation of layers. The upper toluene layer containing the fatty acid methyl esters was transferred to a $2 \mathrm{ml}$ glass vial and crimp sealed with a teflon-lined cap for analysis by GC. GC analysis was conducted using a $30 \mathrm{~m} \times 0.25 \mathrm{~mm}$ (DB225) fused carbon-silica column, coated with cyanopropylphenyl (J \& W Scientific, Folsom, CA, USA). Both injector and detector port temperatures were set at $250^{\circ} \mathrm{C}$. The oven temperature was $170^{\circ} \mathrm{C}$ for $2 \mathrm{~min}$, increased $10^{\circ} \mathrm{C} / \mathrm{min}$ to $190^{\circ} \mathrm{C}$, held for $1 \mathrm{~min}$, then increased $3^{\circ} \mathrm{C} / \mathrm{min}$ up to $220^{\circ} \mathrm{C}$ and was maintained to give a total run time of $30 \mathrm{~min}$. A split ratio of 10:1 and an injection volume of $3 \mu \mathrm{l}$ were used. The chromatograph was equipped with a flame ionization detector, autosampler and autodetector. Sample fatty acid methyl ester peaks were identified by comparing their retention times with those of a standard mixture of fatty acid methyl esters and quantified using a Hewlett Packard 6890 Series Gas Chromatograph with Chemstations version A.04.02. 


\section{Viral titration assay}

Viral titration was performed using confluent RD-ICAM-1 cells seeded in ninety-six-well tissue culture plates (NUNC, Roskilde, Denmark). Cells were infected by either media alone or virus containing media at varying dilutions. Serial 10 -fold dilutions of the samples were prepared and four individual wells were infected with each dilution. For titration of samples six dilutions were prepared. Additionally, for every dilution two controls wells were prepared with media alone. After $4 \mathrm{~d}$ the plates were read and the tissue culture infectious dose at $50 \%\left(\right.$ TCID $\left._{50}\right)$ was calculated. Infected wells were scored based on the cytophatic effect seen, $>50 \%$ cytophatic effect (wells where more than $50 \%$ of their cells are dead) demonstrated by light microscopy was considered a positive result. Viral titres of the samples were determined by cell titration assay using RD-ICAM-1 cells and the viral titre was calculated and expressed as a log value TCID $_{50}$ $\left.\log _{10}\right)^{(47)}$, using the Karber formula for $\operatorname{TCID}_{50}{ }^{(48)}$.

\section{Statistics}

Paired $t$ tests, ANOVA and correlations were performed by GraphPad Prism 4 software (GraphPad Prism, San Diego, CA, USA). $P$ values less than 0.05 were considered as statistically significant.

\section{Results}

Fatty acids were incorporated into the cultured airway epithelial cells in a dose-dependent manner (Fig. 1). EPA and DHA content of cells increased significantly as the concentration of the fatty acids was increased in the medium. The results show that the highest concentration $(400 \mu \mathrm{M})$ of EPA, DHA and AA resulted in 16, 26 and $6 \%$ incorporation into Calu-3 cells, respectively. Pretreatment with $400 \mu \mathrm{M}-$ DHA led to a significant decrease in AA content of Calu-3 cells (Fig. 2, from three independent experiments). It was also found that supplementation of DHA $(400 \mu \mathrm{M})$ resulted in lower cellular levels of AA compared to EPA.

The concentration of lactate dehydrogenase released by Calu-3 cells was similar across all groups supplemented with various concentrations $(0,10,200,400 \mu \mathrm{M})$ of EPA, DHA and AA. Furthermore, visual inspection of the cultured Calu-3 cells after each step confirmed that the cells were viable under all conditions and supplementation regimens.

Infection with either RV-43 or RV-1B resulted in increased release of IL-6, IL-8 and IP-10 (Figs. 3, 4 and 5). DHA $(400 \mu \mathrm{M})$ resulted in a significant $16 \%$ reduction in IL-6 after RV-43 infection (Fig. 3), $29 \%$ reduction in IL-6 after RV-1B infection (Fig. 3), 28\% reduction in IP-10 after RV-43 infection (Fig. 5) and $23 \%$ reduction in IP-10 after RV-1B infection (Fig. 5). DHA suppression of IL-6 release by cells infected with RV-1B occurred in a dosedependent manner (Fig. 3 (b)). DHA content of the cells had a negative correlation with IL-6 (Spearman $\rho-0.775$, $P=0.003$ ) and IP-10 (Spearman $\rho-0.69, P=0.012$ ) levels (Fig. 6). EPA and AA had no effect on the release of cytokines by cultured cells. Pretreatment of cells with the fatty acids had no significant effect on RV replication (data not shown).
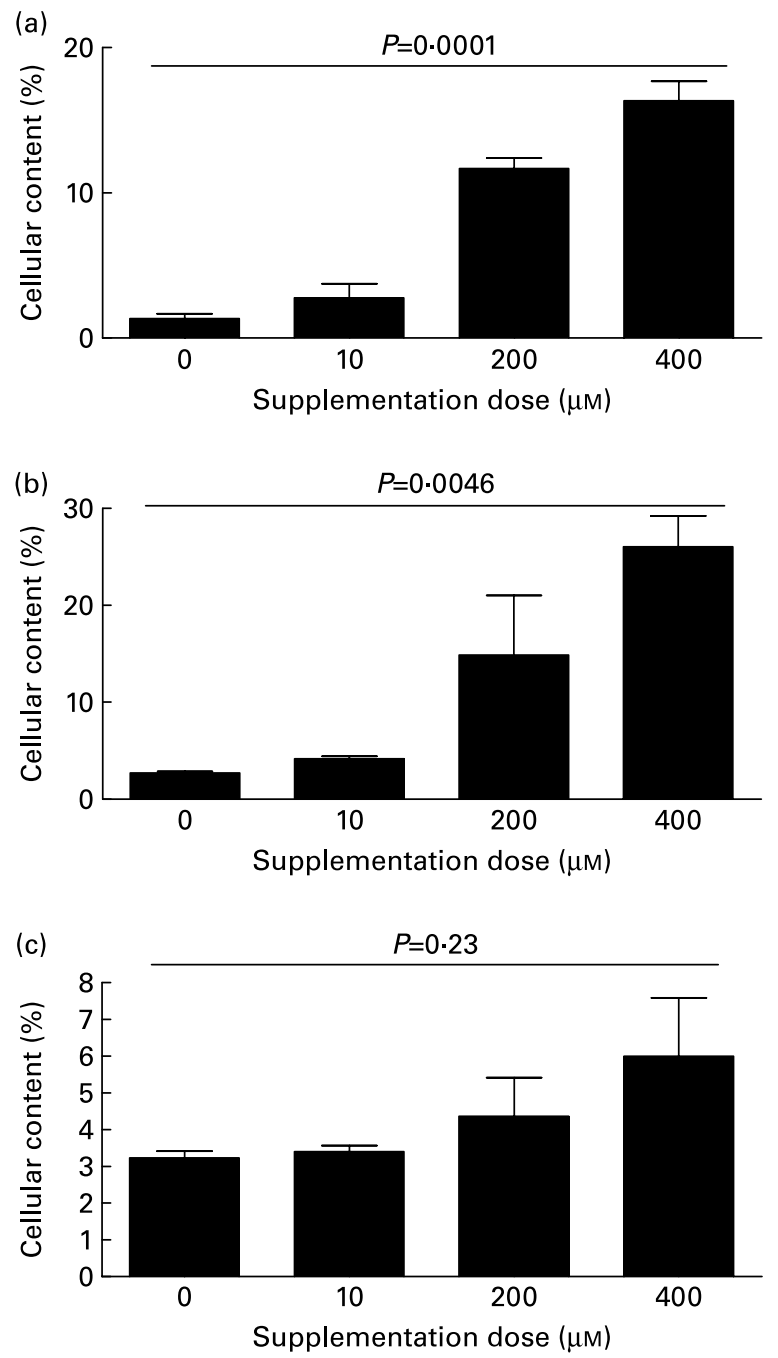

Fig. 1. Cellular content (weight \% of total fatty acids) of EPA (a), DHA (b) and arachidonic acid $(A A ; c)$ in Calu- 3 cells before and after treatment with different concentrations of EPA, DHA and AA. Values are means with their standard deviations depicted by vertical bars (from triplicate experiments).

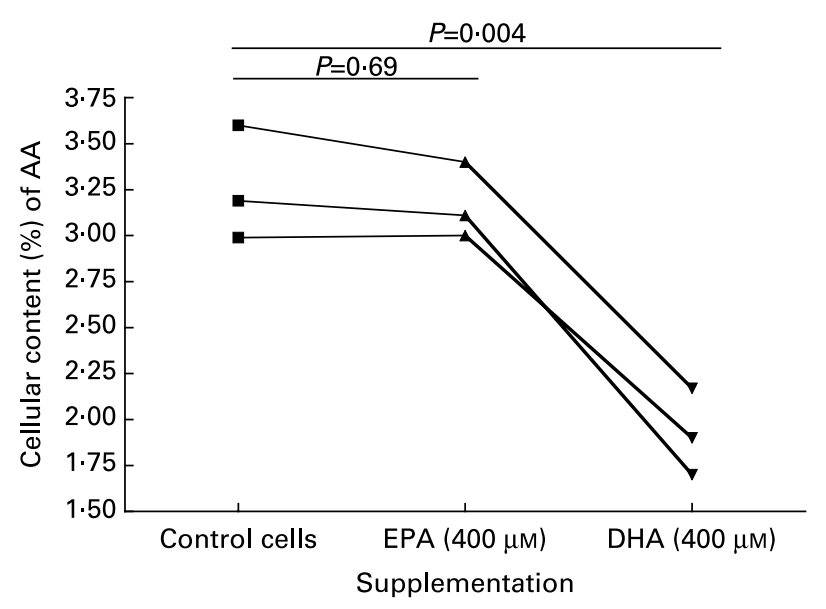

Fig. 2. Arachidonic acid (AA) content (weight $\%$ of total fatty acids) of control Calu- 3 cells compared to the cells supplemented with EPA and DHA. Values are means (from three independent experiments). 

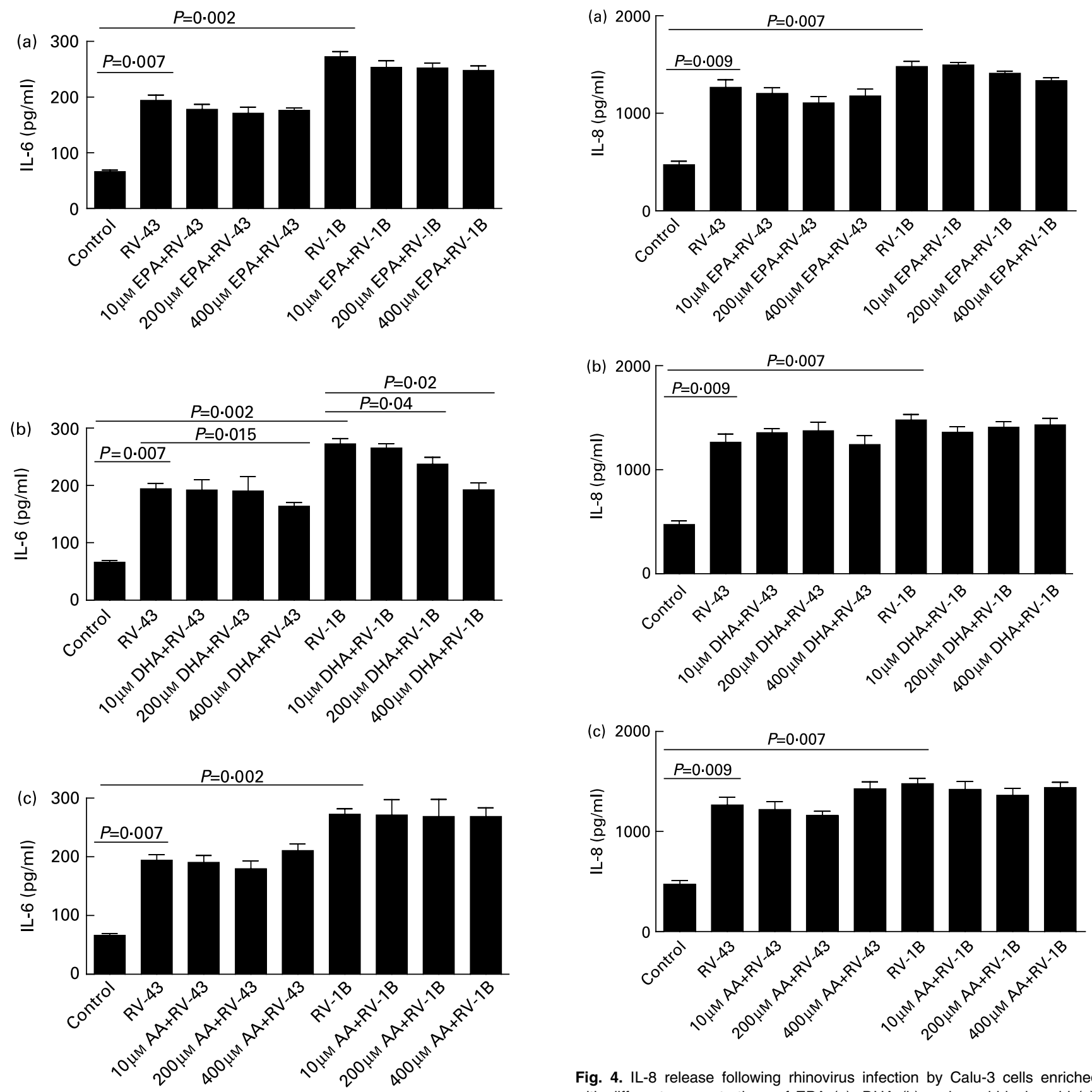

Fig. 3. IL-6 release following rhinovirus (RV) infection by Calu-3 cells enriched with different concentrations of EPA (a), DHA (b) and arachidonic acid (c). Values are means with their standard deviations depicted by vertical bars (from triplicate experiments).

\section{Discussion}

This is the first study investigating the anti-inflammatory effect of EPA and DHA on RV-infected airway epithelial cells (Calu-3 cells). We showed that DHA supplementation increased DHA and decreased AA content of the cells and decreased the release of IL- 6 and IP-10 by cells infected with RV-43 and RV-1B. We also showed that EPA and AA have no effect on the release of inflammatory biomarkers. Furthermore, DHA, EPA and AA have no effect on the replication of RV-43 and RV-1B.

Fig. 4. IL-8 release following rhinovirus infection by Calu-3 cells enriched with different concentrations of EPA (a), DHA (b) and arachidonic acid (c). Values are means with their standard deviations depicted by vertical bars (from triplicate experiments).

The present results showed that EPA, DHA and AA uptake into the cultured airway epithelial cells occurred in a dosedependent manner (Fig. 1). The highest concentration of supplemented fatty acids $(400 \mu \mathrm{M})$ in the present study has been used successfully on cultured porcine cardiomyocytes cells by Nair et al. ${ }^{(46)}$. At the highest concentration $(400 \mu \mathrm{M})$, DHA was most efficiently incorporated, being taken up by $26 \%$, which was nearly twice EPA $(16 \cdot 3 \%)$ and nearly four times the uptake of AA $(6 \%)$. Other studies have reported dose-dependent uptake of LCn-3PUFA into human breast cancer cells after $24 \mathrm{~h}^{(49)}$. It has been shown that higher uptake of DHA compared to EPA into cellular membrane is 

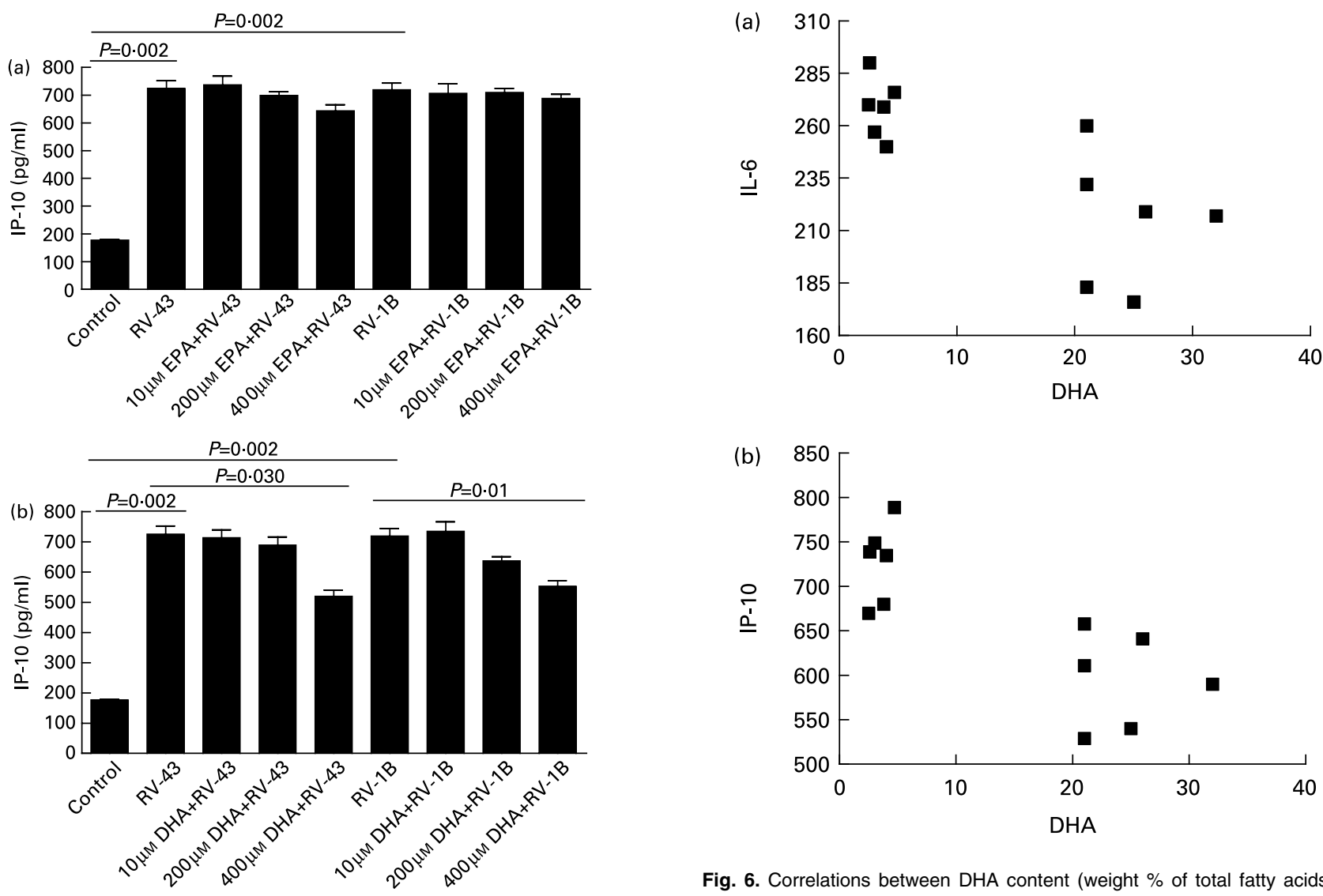

Fig. 6. Correlations between DHA content (weight \% of total fatty acids) of Calu-3 cells $v$. IL-6 (a) and interferon- $\gamma$-induced protein-10 (IP-10; b) levels after rhinovirus-1B infection (from triplicate experiments). (a), Spearman $\rho$

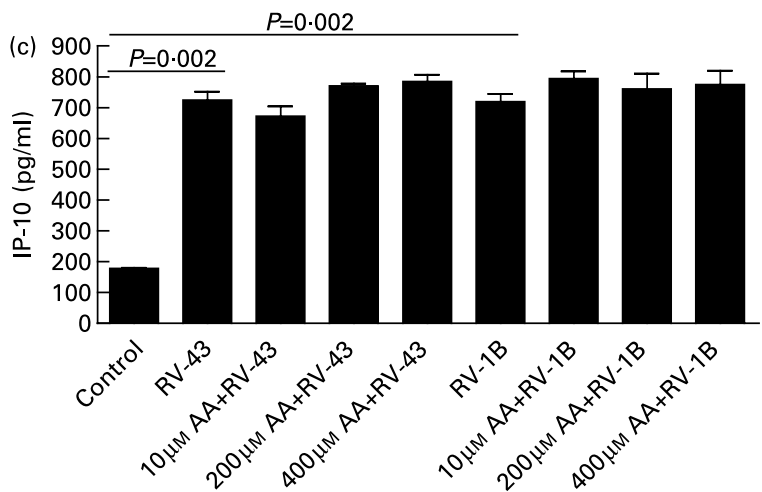
$-0.775, P=0.003$; (b), Spearman $\rho-0.697, P=0.012$.

Supplementation of different concentrations $(10,200$, $400 \mu \mathrm{M})$ of EPA, DHA and AA did not cause any cytotoxic effect on the cultured cells. Cellular viability was confirmed by visual inspection of the cells as well as lactate dehydrogenase released by the cells after supplementation. Lactate dehydrogenase is commonly used as a cell death biomarker ${ }^{(51)}$. In vitro studies have shown that incorporation of high levels of DHA and EPA (more than $500 \mu \mathrm{M}$ ) increases cell cytotoxity and apoptosis in different cell types ${ }^{(52-54)}$. However, in the low concentrations used in the present experiment, no cell toxicity has been observed ${ }^{(24,46)}$.

The present results showed that the concentration of IL-6, IL-8 and IP-10 increased significantly after infection with $\mathrm{RV}-43$ and RV-1B. This is in agreement with the other studies reporting that $\mathrm{RV}$ infection increases the production of IL-6, IL-8 $8^{(33,34,55)}$ and IP-10 $0^{(41)}$ in different types of cultured cells. The present results also showed that presupplementation with DHA $(400 \mu \mathrm{M})$ significantly decreased the release of IL- 6 and IP-10 by Calu-3 cells infected with RV-43 and RV-1B. DHA at a lower concentration $(200 \mu \mathrm{M})$ also decreased IL-6 released by cells infected with RV-1B. DHA content of the cells has a significant negative correlation with pro-inflammatory cytokine levels (Fig. 6). The present data agree with other in vitro ${ }^{(18,19)}$, human $^{(17)}$ and animal studies ${ }^{(21)}$ that have also reported a decrease in IL-6 and IL-8 release after supplementation with LCn-3PUFA. Weldon et al. ${ }^{(26)}$ reported that DHA 
is more potent than EPA in decreasing the production of inflammatory biomarkers. In their study, cellular uptake of DHA and EPA was not compared. Therefore, the present study shows that increased cellular uptake of DHA compared to EPA is probably the explanation for the higher anti-inflammatory effect of DHA.

The present data also showed that DHA decreased IP-10 production of Calu-3 cells infected with RV. There are no previous reports regarding the effect of LCn-3PUFA on the release of IP-10 from airway epithelial cells or other types of cells. It has been reported that response elements of $\mathrm{NF}-\kappa \mathrm{B}$ in the promoter region of the IP-10 gene are involved in transcriptional activation of IP- $10^{(56-58)}$. Therefore, decreased NF- $\kappa \mathrm{B}$ activation may affect the release of IP-10. It has been suggested that IP-10 is involved in viral replication in cells ${ }^{(41)}$. However, the present results show that viral replication of RV-43 and RV-1B was not changed by supplementation with fatty acids. There are no previous studies examining the effect of EPA, DHA and AA on the viral replication of $\mathrm{RV}$ in the literature. Although it appears that the decreased concentration of IP-10 that we observed due to DHA must be independent of viral replication. The viral replication-independent release of IP-10 has been reported previously ${ }^{(59)}$.

The increased cellular content of DHA and decreased content of AA is a probable explanation for the significant anti-inflammatory effect of DHA compared to EPA, as the substitution of DHA for AA is known to reduce production of inflammatory markers ${ }^{(4,17,19,21-23,60,61)}$. The potential effect of LCn-3PUFA on decreasing cytokine production via suppression of NF- $\mathrm{B}$ has been well described ${ }^{(24-27)}$. $\mathrm{NF}-\kappa \mathrm{B}$ has a proven effect on production of a vast variety of pro-inflammatory cytokines (reviewed in Blackwell \& Christman ${ }^{(32)}$ ) including IL-6 and IL- $8^{(33,34)}$. It has been reported that $\mathrm{LC} n$-3PUFA suppress NF- $\mathrm{KB}$ via (1) inactivation of $\operatorname{TLR}^{(27,29,30)}$, (2) blocking I- $\kappa \mathrm{B}$ (NF- $\kappa \mathrm{B}$ inhibitor) degradation and also (3) blocking mitogen-activated protein kinase $^{(24)}$. LCn-3PUFA also inhibit the AA inflammatory pathway via competing with AA to produce less potent inflammatory eicosanoids ${ }^{(4,5,60)}$, decreasing the release of AA from the phospholipids of cellular membrane via decreasing the enzymatic activity of phospholipase $\mathrm{A}_{2}{ }^{(3)}$, decreasing AA content of cells ${ }^{(6)}$ and suppressing the activation of cyclo-oxygenase- 2 which converts $\mathrm{AA}$ to $\mathrm{PG}_{2}$ and thromboxane $2^{(25,29)}$. The probable mechanism for this suppression is also related to inactivation of $\operatorname{TLR}^{(29,30)}$. Therefore the most likely mechanisms by which DHA decreased the production of inflammatory biomarkers in the present study is its inhibitory effect on (1) NF- $\mathrm{KB}$ activation and (2) AA inflammatory pathway, both via decreasing TLR activity.

In summary, we found that DHA decreased inflammation in airway epithelial cells infected with RV-43 and RV-1B via decreasing IL- 6 and IP-10 release. It was found that because of the higher cellular uptake of DHA, after supplementing with equivalent amounts of EPA and DHA, DHA content of airway epithelial cells was higher than EPA. DHA also decreased cellular content of AA. It is likely that these two findings explain the anti-inflammatory effect of DHA. Therefore, DHA supplementation may be useful in decreasing the inflammatory response of airway epithelial cells to RV infection.

\section{Acknowledgements}

This study was supported by a $\mathrm{PhD}$ scholarship fund by Tehran University of Medical Sciences. The authors would like to acknowledge the assistance of Terry Grissell, Melinda Phang, Michelle Gleeson, Kellie Fakes, Katie Baines and Heather Powell. A. S. performed the experiments, did the laboratory and statistical analysis, and prepared the manuscript. L. G. W., M. L. G., P. G. G. and P. A. B. W. contributed to the design and interpretation of the experiments and reviewed the manuscript. None of the authors have any conflict of interest to declare.

\section{References}

1. Kromann N \& Green A (1980) Epidemiological studies in the Upernavik district, Greenland. Incidence of some chronic diseases 1950-1974. Acta Med Scand 208, 401-406.

2. Dyerberg J \& Bang HO (1979) Haemostatic function and platelet polyunsaturated fatty acids in Eskimos. Lancet 2, 433-435.

3. Martin RE (1998) Docosahexaenoic acid decreases phospholipase A2 activity in the neurites/nerve growth cones of PC12 cells. J Neurosci Res 54, 805-813.

4. Simopoulos AP (2002) Omega-3 fatty acids in inflammation and autoimmune diseases. J Am Coll Nutr 21, 495-505.

5. Tamura Y, Terano J, Saito A, et al. (1995) Enhancement of PGI2 formation by EPA in rat vascular smooth muscle cells. In Nutrition, Lipids, Health and Disease, p. 169 [ASH Ong, E Niki and L Packer, editors]. Champaign, IL: The American Oil Chemists' Society.

6. Kang JX, Man SF, Brown NE, et al. (1992) Essential fatty acid metabolism in cultured human airway epithelial cells. Biochim Biophys Acta 1128, 267-274.

7. Harbige LS (2003) Fatty acids, the immune response, and autoimmunity: a question of $n-6$ essentiality and the balance between $n-6$ and $n$-3. Lipids 38, 323-341.

8. Calder PC (2001) Polyunsaturated fatty acids, inflammation, and immunity. Lipids 36, 1007-1024.

9. Glew R (1997) Lipid metabolism. In Textbook of Biochemistry, 4th ed., pp. 434 [T Devlin, editor]. New York: Wiley-Liss.

10. Lee TH, Hoover RL, Williams JD, et al. (1985) Effect of dietary enrichment with eicosapentaenoic and docosahexaenoic acids on in vitro neutrophil and monocyte leukotriene generation and neutrophil function. $N$ Engl J Med 312, 1217-1224.

11. Mann J \& Skeaff M (1998) Lipids. In Essentials of Human Nutrition, p. 637 [J Mann and S Truswell, editors]. Oxford: Oxford University Press.

12. Calder P (2001) $\omega-3$ Polyunsaturated fatty acids, inflammation and immunity. In Fatty Acids and Lipids - New Findings, p. 109 [T Hamazaki and H Okuyama, editors]. Basel: Karger.

13. Goldman DW, Pickett WC \& Goetzl EJ (1983) Human neutrophil chemotactic and degranulating activities of leukotriene B5 (LTB5) derived from eicosapentaenoic acid. Biochem Biophys Res Commun 117, 282-288.

14. Jatakanon A, Uasuf C, Maziak W, et al. (1999) Neutrophilic inflammation in severe persistent asthma. Am J Respir Crit Care Med 160, 1532-1539.

15. Sun YC \& Chu HW (2004) Do neutrophils actively participate in airway inflammation and remodeling in asthma? Chin Med J (Engl) 117, 1739-1742.

16. Yasui K, Kobayashi N, Yamazaki T, et al. (2005) Neutrophilic inflammation in childhood bronchial asthma. Thorax 60, 704-705.

17. Browning LM, Krebs JD, Moore CS, et al. (2007) The impact of long chain $n$-3 polyunsaturated fatty acid supplementation on inflammation, insulin sensitivity and CVD risk in a group of 
overweight women with an inflammatory phenotype. Diabetes Obes Metab 9, 70-80.

18. Bryan D, Forsyth K, Hart P, et al. (2006) Polyunsatuated fatty acids regulate cytokine and prostaglandin E2 production by respiratory cells in response to mast cell mediators. Lipids $\mathbf{4 1}$, $1101-1107$.

19. Abbate R, Gori AM, Martini F, et al. (1996) n-3 PUFA supplementation, monocyte PCA expression and interleukin-6 production. Prostaglandins Leukot Essent Fatty Acids 54, 439-444.

20. Bryan DL, Forsyth KD, Hart PH, et al. (2006) Polyunsaturated fatty acids regulate cytokine and prostaglandin E2 production by respiratory cells in response to mast cell mediators. Lipids 41, $1101-1107$

21. Zeitlin L, Segev E, Fried A, et al. (2003) Effects of long-term administration of $n-3$ polyunsaturated fatty acids (PUFA) and selective estrogen receptor modulator (SERM) derivatives in ovariectomized (OVX) mice. J Cell Biochem 90, 347-360.

22. Fritsche KL, Anderson M \& Feng C (2000) Consumption of eicosapentaenoic acid and docosahexaenoic acid impair murine interleukin-12 and interferon-gamma production in vivo. J Infect Dis 1821, Suppl. 1, S54-S61.

23. Skuladottir IH, Petursdottir DH \& Hardardottir I (2007) The effects of omega-3 polyunsaturated fatty acids on TNF-alpha and IL-10 secretion by murine peritoneal cells in vitro. Lipids 42, 699-706.

24. Moon DO, Kim KC, Jin CY, et al. (2007) Inhibitory effects of eicosapentaenoic acid on lipopolysaccharide-induced activation in BV2 microglia. Int Immunopharmacol 7, 222-229.

25. Horia E \& Watkins BA (2007) Complementary actions of docosahexaenoic acid and genistein on COX-2, PGE2 and invasiveness in MDA-MB-231 breast cancer cells. Carcinogenesis 28, 809-815.

26. Weldon SM, Mullen AC, Loscher CE, et al. (2007) Docosahexaenoic acid induces an anti-inflammatory profile in lipopolysaccharide-stimulated human THP-1 macrophages more effectively than eicosapentaenoic acid. J Nutr Biochem 18, $250-258$.

27. Jia Y \& Turek JJ (2005) Altered NF-kappaB gene expression and collagen formation induced by polyunsaturated fatty acids. J Nutr Biochem 16, 500-506.

28. Lo CJ, Chiu KC, Fu M, et al. (1999) Fish oil decreases macrophage tumor necrosis factor gene transcription by altering the NF kappa B activity. J Surg Res 82, 216-221.

29. Lee JY, Zhao L, Youn HS, et al. (2004) Saturated fatty acid activates but polyunsaturated fatty acid inhibits Toll-like receptor 2 dimerized with Toll-like receptor 6 or 1. J Biol Chem 279, $16971-16979$.

30. Lee JY, Sohn KH, Rhee SH, et al. (2001) Saturated fatty acids, but not unsaturated fatty acids, induce the expression of cyclooxygenase-2 mediated through Toll-like receptor 4 . J Biol Chem 276, 16683-16689.

31. Barton GM \& Medzhitov R (2003) Toll-like receptor signaling pathways. Science 300, 1524-1525.

32. Blackwell TS \& Christman JW (1997) The role of nuclear factor-kappa B in cytokine gene regulation. Am J Respir Cell Mol Biol 17, 3-9.

33. Zhu Z, Tang W, Ray A, et al. (1996) Rhinovirus stimulation of interleukin-6 in vivo and in vitro. Evidence for nuclear factor kappa B-dependent transcriptional activation. J Clin Invest 97, 421-430.

34. Zhu Z, Tang W, Gwaltney JM Jr, et al. (1997) Rhinovirus stimulation of interleukin-8 in vivo and in vitro: role of NF-kappaB. Am J Physiol 273, L814-L824.

35. Calder $P$ (1996) Immunomodulatory and anti-inflammatory effects of $\omega-3$ polyunsaturated fatty acids. Proc Nutr Soc 55, $737-774$.
36. Calder P (1998) Dietary fatty acids and lymphocyte functions. Proc Nutr Soc 57, 487-502.

37. Dreschers S, Dumitru CA, Adams C, et al. (2007) The cold case: are rhinoviruses perfectly adapted pathogens? Cell Mol Life Sci 64, 181-191.

38. Nicholson KG, Kent J \& Ireland DC (1993) Respiratory viruses and exacerbations of asthma in adults. Br Med J 307, 982-986.

39. Johnston SL, Pattemore PK, Sanderson G, et al. (1995) Community study of role of viral infections in exacerbations of asthma in 9-11 year old children. Br Med J 310, 1225-1229.

40. Grunberg K, Timmers MC, de Klerk EP, et al. (1999) Experimental rhinovirus 16 infection causes variable airway obstruction in subjects with atopic asthma. Am J Respir Crit Care Med 160, 1375-1380.

41. Spurrell JC, Wiehler S, Zaheer RS, et al. (2005) Human airway epithelial cells produce IP-10 (CXCL10) in vitro and in vivo upon rhinovirus infection. Am J Physiol Lung Cell Mol Physiol 289, L85-L95.

42. Subauste MC, Jacoby DB, Richards SM, et al. (1995) Infection of a human respiratory epithelial cell line with rhinovirus. Induction of cytokine release and modulation of susceptibility to infection by cytokine exposure. J Clin Invest 96, 549-557.

43. Gern JE (2002) Rhinovirus respiratory infections and asthma. Am J Med 112, Suppl. 6A, 19S-27S.

44. Yamaya M \& Sasaki H (2003) Rhinovirus and asthma. Viral Immunol 16, 99-109.

45. Calder PC (2001) Omega 3 polyunsaturated fatty acids, inflammation and immunity. World Rev Nutr Diet 88, 109-116.

46. Nair SS, Leitch J \& Garg ML (1999) Specific modifications of phosphatidylinositol and nonesterified fatty acid fractions in cultured porcine cardiomyocytes supplemented with $n-3$ polyunsaturated fatty acids. Lipids 34, 697-704.

47. Reed L \& Muench H (1938) A simple method of estimating fifty percent endpoints. Am J Hygiene 27, 493-497.

48. Karber G (1931) $50 \%$ end-point calculation. Arch Exp Pathol Pharmak 162, 480-483.

49. Hatala MA, Rayburn J \& Rose DP (1994) Comparison of linoleic acid and eicosapentaenoic acid incorporation into human breast cancer cells. Lipids 29, 831-837.

50. Croset M \& Lagarde M (1986) In vitro incorporation and metabolism of icosapentaenoic and docosahexaenoic acids in human platelets - effect on aggregation. Thromb Haemost 56, $57-62$.

51. Shahrzad S, Cadenas E, Sevanian A, et al. (2002) Impact of water-dispersible beadlets as a vehicle for the delivery of carotenoids to cultured cells. Biofactors 16, 83-91.

52. Sagar PS, Das UN, Koratkar R, et al. (1992) Cytotoxic action of cis-unsaturated fatty acids on human cervical carcinoma (HeLa) cells: relationship to free radicals and lipid peroxidation and its modulation by calmodulin antagonists. Cancer Lett $\mathbf{6 3}$, 189-198.

53. Kageyama K, Yamada R, Otani S, et al. (2000) Cytotoxicity of docosahexaenoic acid and eicosapentaenoic acid in tumor cells and the dependence on binding to serum proteins and incorporation into intracellular lipids. Oncol Rep 7, 79-83.

54. Chi TY, Chen GG \& Lai PB (2004) Eicosapentaenoic acid induces Fas-mediated apoptosis through a p53-dependent pathway in hepatoma cells. Cancer J 10, 190-200.

55. Zalman LS, Brothers MA, Dragovich PS, et al. (2000) Inhibition of human rhinovirus-induced cytokine production by AG7088, a human rhinovirus 3C protease inhibitor. Antimicrob Agents Chemother 44, 1236-1241.

56. Majumder S, Zhou LZ, Chaturvedi P, et al. (1998) p48/STAT1alpha-containing complexes play a predominant role in induction of IFN-gamma-inducible protein, $10 \mathrm{kDa}$ (IP-10) by IFN-gamma alone or in synergy with TNF-alpha. J Immunol 161, 4736-4744. 
57. Nazar AS, Cheng G, Shin HS, et al. (1997) Induction of IP-10 chemokine promoter by measles virus: comparison with interferon-gamma shows the use of the same response element but with differential DNA-protein binding profiles. J Neuroimmunol 77, 116-127.

58. Wu C, Ohmori Y, Bandyopadhyay S, et al. (1994) Interferonstimulated response element and NF kappa B sites cooperate to regulate double-stranded RNA-induced transcription of the IP-10 gene. J Interferon Res 14, 357-363.
59. Korpi-Steiner NL, Bates ME, Lee WM, et al. (2006) Human rhinovirus induces robust IP-10 release by monocytic cells, which is independent of viral replication but linked to type I interferon receptor ligation and STAT1 activation. J Leukoc Biol 80, 1364-1374.

60. Mori TA \& Beilin LJ (2004) Omega-3 fatty acids and inflammation. Curr Atheroscler Rep 6, 461-467.

61. Simopoulos AP (1991) Omega-3 fatty acids in health and disease and in growth and development. Am J Clin Nutr 54, 438-463. 